\title{
Meningkatkan Hasil Belajar Mata Pelajaran Tauhid Melalui Metode Sing a Song di Kelas I Pondok Pesantren "Darul Muhajirin" Purwantoro
}

\author{
Ririn Nuraini, Nia Yunia Sari, Ilma Umi Robiqoh \\ Institut Agama Islam Riyadlotul Mujahidin Ngabar Ponorogo \\ ririnnuraini453@gmail.com, sariyunia01@gmail.com, ilma.umi.robiqoh@gmail.com
}

\begin{abstract}
Abstrak
Penelitian ini bertujuan untuk mengetahui efektifitas metode pembelajaran Sing a Sing untuk meningkatkan hasil belajar siswa kelas I Pondok Pesantren"Darul Muhajirin" Purwantoro dalam mata pelajaran Tajwid melalui penerapan metode Sing $a$ Song. Subjek penelitian adalah kelas I Pondok Pesantren"Darul Muhajirin" Purwantoro yang berjumlah 24 siswa, terdiri atas 10 laki-laki dan 14 perempuan. Penelitian ini merupakan penelitian tindakan kelas (PTK) yang terdiri atas dua siklus dengan desain setiap siklus terdiri atas empat tahapan, yaitu tahap pertama adalah Planning (merencanakan), tahap kedua adalah acting (melaksanakan), observing (observasi) dan tahap ketiga adalah reflecting (merefleksi). Data penelitian didapatkan selama penelitian tindakan sampai penilaian akhir tindakan. Hasil penelitian menunjukkan bahwa pada hasil tes awal setelah adanya tindakan pada siklus I dari 16 siswa terdapat 8 siswa yang tuntas $(66,67 \%)$, sedangkan pada siklus II jumlah siswa yang tuntas sebanyak 22 siswa (91,67\%). Dengan demikian dapat dibuktikan bahwa penerapan metode Sing a Song pada mata pelajaran Tauhid kelas I Pondok Pesantren"Darul Muhajirin" Purwantoro dalam Tauhid Bab III
\end{abstract}


Hal Nabi dan Rosul memberikan dampak positif dalam meningkatkan hasil belajar siswa.

Kata kunci: Hasil belajar, Metode Sing a Song

\section{Pendahuluan}

Pembelajaran merupakan sebuah proses yang bersifat dinamis yang memiliki pengaruh besar terhadap kualitas pendidikan. Persoalan yang muncul selalu berbeda, walaupun beberapa kondisi yang ada masih sama. Sehubungan dengan hal tersebut, guru perlu selalu berinovasi terkait dengan pembelajaran dan evaluasi yang dilakukan. Selama pendidikan masih ada, maka selama itu pula masalah-masalah tentang pendidikan akan selalu muncul. ${ }^{1}$ Sejauh ini guru telah banyak menerapkan metode pembelajaran, namun kompetensi siswa belum mencapai standar yang diharapkan. Hal ini dapat dilihat dari hasil test siswa baik test lisan maupun test tulis beberapa siswa belum mencapai Ketuntasan Kriteria Minimal (KKM). Siswa masih kesulitan dalam memahami mata pelajaran Tauhid Bab III Hal Nabi dan Rosul.

Hasil belajar merupakan pencapaian tujuan pendidikan pada siswa yang mengikuti proses belajar mengajar dalam aspek afektif, kognitif, dan psikomotor. Di dalam proses pembelajaran, guru sebagai pengajar sekaligus sebagai pendidik memegang peranan dan tanggung jawab yang besar dalam belajar. Di samping itu juga keberhasilan peserta peserta didik dipengaruhi oleh kualitas pengajaran dan faktor dari siswa itu sendiri. ${ }^{2}$

${ }^{1}$ Imam Rohani. "Conflict Management between Students at the Integrated Islamic Elementary School Qurrota A'yun Ponorogo." In 6th International Conference on Community Development (ICCD 2019), 349:250-253. Atlantis Press, 2019.

${ }^{2}$ Nana Sudjana, Penilaian Hasil Proses Belajar Mengajar (Bandung: Remaja Rosdakarya, 2009), 22. 
Pelaksanaan pendidikan tidak boleh serta merta dilakukan secara sembrono karena akan berdampak negatif terhadap peserta didik. Maka dari itu, hal yang paling menunjang dalam terwujudnya pendidikan yang berkarakter adalah gurunya. Guru inovatif yakni seorang pendidik yang kinerjanya tidak hanya terpaku kepada sesuatu yang telah dibakukan, namun seluruh aktivitas yang ditunjukkan oleh guru dalam tanggung jawabnya sebagai orang yang mengemban suatu amanat dan tanggung jawab untuk mendidik, mengajar, membimbing, mengarahkan dan memandu peserta didik ke arah suatu upaya mengembangkan inovasi baru dalam rangka menggiring perkembangan peserta didik ke arah kedewasaan mentalspiritual maupun fisik-psikologis.

Penilaian kinerja guru dilakukan untuk mendapatkan guru bermutu baik dan profesional. Melalui upaya yang berkesinambungan, diharapkan terjadi perbaikan kualitas yang berkesinambungan pula (continuous quality improvement). ${ }^{3} \mathrm{Di}$ mana nantinya dengan kinerja guru yang baik dapat berbanding lurus dengan hasil belajar siswa. Guru selaku tenaga pendidik yang berinteraksi langsung dengan peserta didik seyogyanya memahami perannya sebagai guru. Dalam pembelajaran yang dilakukan perlu memilih metode yang tepat dengan materi pembelajaran. Dalam pembelajaran mata pelajaran Tauhid kelas I guru sebaiknya memilih stratetegi, pendekatan, metode, media, dan teknik yang tepat dalam mengajar. Dengan demikian, peneliti berupaya mencari salah satu solusi pemecahannya yaitu dengan menerapkan metode sing a song.

Pada proses pembelajaran dengan metode sing a song, siswa menerima materi pelajaran yang terkandung dalam lagu dari guru sebagai tahap awal dari proses belajar dan

3 Ririn Nuraini, "Pengembangan Self-Esteem Sebagai Upaya Peningkatan Kinerja Pendidik di TKIT 2 Qurrota A'yun Ponorogo, “dalam Jurnal Muslim Heritage Volume 3, No. 2, (November, 2018), 343. 
pembelajaran. Pemahaman yang dimaksudkan yaitu siswa mampu memahami konsep materi melalui proses pengenalan lagu. Siswa dapat memahami makna kalimat dari bernyanyi. Kegiatan bernyanyi adalah salah satu kegiatan yang digemari oleh anak. Sehingga pengalaman bernyanyi inipun bisa menjadi salah satu kepuasan padanya. Selain itu bernyayi bisa menjadi sarana untuk mengungkapkan pikiran dan perasaanya. Dengan metode Sing a Song ini diharapkan siswa akan lebih mudah memahami materi pelajaran. ${ }^{4}$

\section{Landasan Teori}

Tauhid adalah aqidah bawaan manusia. Allah telah menciptakan manusia memiliki fitrah beriman kepada-Nya dan mentauhidkan-Nya. Manusia itu dilahirkan dalam keadaan mengimani keberadaan Allah bahwa tidak ada yang berhak diibadahi selain Dia, dan tidak ada Tuhan selain Dia. ${ }^{5}$ Dengan mempelajari ilmu aqidah, membuka wawasan umat Muslim tentang cara meningkatkan keimanan dalam beragama. Salah satu ilmu aqidah yang penting untuk dipelajari adalah tauhid. Arti tauhid diketahui sebagai ilmu yang mempelajari tentang sifat keesaan Allah. Dengan makna Allah itu satu, Dzat yang memiliki segala kesempurnaan dan tidak ada satu pun yang bisa menggantikannya.

Selain itu, arti tauhid juga dipahami sebagai sikap meyakini bahwa Allah Maha Suci yang tidak memiliki kekurangan sedikit pun, seperti yang dimiliki oleh makhluk hidup ciptaannya. Bukan hanya itu, mempelajari arti tauhid juga termasuk meyakini kebenaran seluruh ajaran Allah yang

${ }^{4}$ Khaniffatur Rokhmah, "Penggunaan Metode Sing a Song Dalam Upaya Peningkatan Motivasi dan Hasil Belajar Bahasa Inggris Siswa Kelas IV SDN Tegalsari Adimulyo Tahun Pelajaran 2013/2014, "dalam UNS-F. KIP Jur. Pendidikan Guru Sekolah Dasar-X.7211049-2016. 2016 , 2.

${ }^{5}$ Imam Zarkasyi, Usuluddin (Aqa'id).Bandung:Trimurti:2014. Hal.2 
diturunkan dan disebarkan oleh para Rasul-Nya. Masalah belajar adalah masalah bagi setiap manusia, dengan belajar manusia memperoleh keterampilan, kemampuan sehingga terbentuklah sikap dan bertambahlah ilmu pengetahuan. Jadi hasil belajar itu adalah suatu hasil nyata yang dicapai oleh siswa dalam usaha menguasai kecakapan jasmani dan rohani di sekolah yang diwujudkan dalam bentuk raport pada setiap semester.

Untuk mengetahui perkembangan sampai di mana hasil yang telah dicapai oleh seseorang dalam belajar, maka harus dilakukan evaluasi. Untuk menentukan kemajuan yang dicapai maka harus ada kriteria (patokan) yang mengacu pada tujuan yang telah ditentukan sehingga dapat diketahui seberapa besar pengaruh strategi belajar mengajar terhadap keberhasilan belajar siswa. Hasil belajar siswa keberhasilan yang dicapai oleh siswa, yakni prestasi belajar siswa di sekolah yang mewujudkan dalam bentuk nilai tuntas.

Metode pembelajaran Sing a Song adalah nyanyikanlah sebuah lagu, atau nyanyikan sebuah lagu, sangat mudah digunakan dalam proses belajar mandiri maupun kelompok. ${ }^{6}$ Metode ini tidak jauh berbeda dengan metode yang lain yang membedakan hanyalah media yang digunakan selama proses pembelajaran. Siswa menerima materi pelajaran yang terkandung dalam lagu dari guru sebagai tahap awal dari proses belajar dan pembelajaran. Pemahaman yang dimaksudkan yaitu siswa mampu memahami konsep unsur-unsur bahasa dan menghafal materi yang ada melalui proses pengenalan lagu sehingga dapat diterapkan dalam berkomunikasi.

${ }^{6}$ Fandy's (2010). Metode pembelajaran dengan lagu. diperoleh 10 Oktober 2012 dari //http.Fandi's.blogspot

${ }^{7}$ Schiller P. (2005). 20 Tips Start Smart! Memompa Kecerdasann Sejak Dini. Jakarta: Erlangga 


\section{Metode Penelitian}

Penelitian ini dilaksanakan di Pondok Pesantren "Darul Muhajirin" pada mata pelajaran Tauhid Bab III Hal Nabi dan Rosul. Subjek penelitian adalah kelas I yang terdiri dari 24 siswa, yaitu 10 siswa dan 14 siswi tahun ajaran 2021/2022. Penelitian tindakan kelas dilaksanakan dengan tahapan perencanaan, tindakan, observasi, dan evaluasi/refleksi dan disajikan dalam dua siklus. Data dikumpulkan, kemudian dipetakan dan dianalisis sejak penelitian tindakan dimulai. Selanjutnya data dikembangkan selama proses refleksi sampai proses penyusunan laporan.

Untuk mendapatkan data penelitian yang valid dan dapat dipertangungjawabkan, maka dalam dalam penelitian ini digunakan beberapa instrumen pembantu, yaitu lembar observasi, dan lembar hasil tes siswa. Dalam penelitian ini aspek yang diteliti adalah siswa, oleh karena itu yang menjadi indikator kinerja adalah perubahan yang terjadi pada siswa baik dalam proses pembelajaran maupun dalam hasil belajar.

\section{Teknik Penelitian}

Penelitian Tindakan Kelas adalah penelitian praktis untuk memperbaiki pembelajaran di dalam kelas. Merupakan salah satu upaya guru atau praktisi dalam bentuk berbagai kegiatan yang dilakukan untuk memperbaiki dan meningkatkan mutu pembelajaran di kelas. ${ }^{8}$

Penelitian ini terdiri dari dua siklus dengan empat tahapan yaitu, tahap pertama adalah Planning (merencanakan), tahap kedua adalah acting (melaksanakan), observing (observasi) dan tahap ketiga adalah reflecting (merefleksi). Dalam setiap siklus penelitian ini akan dilaksanakan sesuai dengan indicator yang akan dicapai, sehingga dapat

8 Anas Salahudin, Penelitian Tindakan Kelas.Bandung: Pustaka setia:2015,hal. 24. 
memperoleh data yang dibutuhkan sebagai kesimpulan atas jawaban pertanyaan atau masalah.

\section{Instrumen Penelitian}

Jenis data yang digunakan dalam penelitian ini terdiri dari (a) data kualitatif diperoleh dari hasil observasi kegiatan guru dan siswa pada setiap tindakan berupa lembar observasi yang terdiri dari: (i) lembar observasi terhadap guru (peneliti) dalam menerapkan rencana pembelajaran, (ii) lembar observasi terhadap siswa mengenai kegiatan selama proses pembelajaran, (b) data kuantitatif diperoleh dari hasil evaluasi yang diberikan pada setiap akhir tindakan yang berfungsi sebagai informasi tentang kemajuan siswa dalam memahami materi yang diajarkan. Data ini diambil dengan menggunakan tes yang meliputi tes awal dan tes setiap akhir tindakan.

\section{Hasil dan Pembahasan \\ Pra Tindakan}

Kegiatan pembelajaran Tauhid di kelas I dilaksanakan dua kali dalam satu pekan yakni hari Senin dan Jum'at. Pembahasan Bab Nabi dan Rosul dimulai pada pertemuan ke 14 pada hari Jum'at, 06 Agustus 2021. Pembelajaran dilakukan dengan menggunakan metode ceramah lalu diakhiri dengan penugasan untuk menghafal 25 Nabi dan Rosul. Tes hafalan dilakukan pada pertemuan ke 15, tepatnya pada hari Senin 9 Agustus 2021. Hasil tes menunjukkan bahwa dari 24 siswa, 11 siswa $(45.83 \%)$ dinyatakan tuntas, sementara untuk 13 siswa lainnya $(54,17 \%)$ dinyatakan belum tuntas. Adapun cara yang dilakukan peneliti adalah melakukan diskusi dengan siswa yang belum tuntas. Secara umum siswa berkomentar bahwa masih merasa sulit dalam menghafal nama-nama Nabi dan Rosul. Berdasarkan hasil tersebut maka peneliti melanjutkan ke tindakan siklus I. 


\section{Siklus I}

Kegiatan Siklus I dilaksanakan pada pertemuan ke 16 Tepatnya hari Jum'at 13 Agustus 2021. Pada pelaksanaanya guru telah menggunakan metode Sing a Song. Sebagai langkah awal guru menanyakan kembali tentang materi Nabi dan Rosul yang telah dipelajari lalu memberikan gambaran tentang cara menghafal menggunakan nyanyian. Pertama, guru meminta untuk semua siswa membuka catatan 25 Nama-nama Nabi dan Rosul, lalu mengintruksikan kepada siswa untuk memperhatikan guru untuk mencontohkan bagaiman caranya menghafal dengan nyanyian. Setelah dirasa cukup untuk mengerti dan memahami nada-nada nyayiannya guru mengintruksikan kepada siswa untuk mempraktekkan sendiri. Kemudian guru mengintruksikan kepada sisw untuk menutup buku catatannya kemudian diulangi satu kali lagi bernyanyinya.

Sebelum memasuki evaluasi guru memberikan waktu 20 Menit kepada siswa untuk menghafalkan kembali mengenai materi 25 nama Nabi dan Rosul. Adapun penilaian atau evaluasi yang digunakan adalah dengan tes lisan individual yaitu siswa menghafalkan dengan cara bernyanyi ditempat duduk masing-masing Kemudian guru memanggil satu persatu nama sesuai dengan nomor absen untuk maju kedepan. Hasil penilaian Siklus I dapat dilihat pada table berikut:

\begin{tabular}{|c|l|l|}
\hline NO & \multicolumn{1}{|c|}{ NAMA } & \multicolumn{1}{c|}{ KETUNTASAN } \\
\hline 1 & Abdulloh & Tuntas \\
\hline 2 & Ana & Tuntas \\
\hline 3 & Andrean & Tuntas \\
\hline 4 & Adnan & Tuntas \\
\hline 5 & Aisyah & Tidak Tuntas \\
\hline 6 & Arya & Tidak Tuntas \\
\hline 7 & Auliya & Tuntas \\
\hline 8 & Bella & Tuntas \\
\hline
\end{tabular}




\begin{tabular}{|c|l|l|}
\hline NO & \multicolumn{1}{|c|}{ NAMA } & \multicolumn{1}{c|}{ KETUNTASAN } \\
\hline 9 & Dhesti & Tuntas \\
\hline 10 & Erisa & Tuntas \\
\hline 11 & Ferdi & Tuntas \\
\hline 12 & Gilang & Tidak Tuntas \\
\hline 13 & Noval & Tidak Tuntas \\
\hline 14 & Okta & Tidak Tuntas \\
\hline 15 & Putri & Tuntas \\
\hline 16 & Rahma & Tuntas \\
\hline 17 & Rasya & Tuntas \\
\hline 18 & Reza & Tidak Tuntas \\
\hline 19 & Riki & Tuntas \\
\hline 20 & Salwa & Tuntas \\
\hline 21 & Yanoviya & Tuntas \\
\hline 22 & Yiyin & Tidak Tuntas \\
\hline 23 & Yasdiyas & Tuntas \\
\hline 24 & Zahra & Tidak Tuntas \\
\hline
\end{tabular}

Tabel 2. Hasil Evaluasi Tes Akhir Tindakan Siklus II

Dari hasil evaluasi tes akhir tindakan siklus II menunjukkan 22 siswa yang telah tuntas (91.67\%) sedangkan 2 Siswa lainnya belum tuntas $(8,33 \%)$. Dari hasil di atas dapat disimpulkan bahwa dengan menggunakan metode Sing and Song pada mata pelajaran Tauhid Bab III Hal Nabi dan Rosul dapat meningkatkan hasil belajar yang signifikan pada kelas 1 Pondok Pesantren "Darul Muhajirin" Purwantoro.

\section{Kesimpulan}

Berdasarkan penelitian yang sudah dilaksanakan peneliti menyimpulkan bahwa dengan menggunakan metode Sing a Song pada mata pelajaran Tauhid Bab Nabi dan Rosul dapat meningkatkan hasil belajar yang signifikan. Hal itu dapat ditunjukkan dengan adanya peningkatan hasil kerja siswa dan 
pemahaman siswa yang mengarah kepada penerapan siswa menghafal nama-nama Nabi dan Rosul sesuai kaidah ilmu Tauhid. Hal tersebut dapat dilihat dari diagram hasil dengan ditunjukkan dalam grafik berikut:

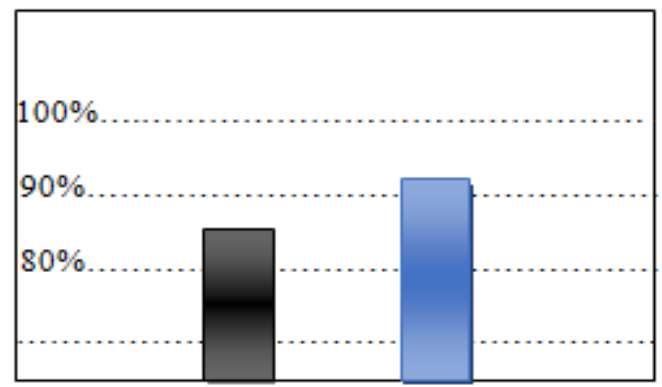

目: Siklus I

Siklus II

Grafik 1: Peningkatan hasil evaluasi belajar siklus I dan II

\section{Saran}

Diharapkan kepada guru mata pelajaran PAI agar dapat memilih teknik dan metode yang tepat sesuai dengan materi pembelajaran agar pembelajaran dapat mewujudkan pemahaman yang mengarah pada hasil belajar. Terutama pada mata pelajaran Tauhid, diharapkan pula siswa tidak hanya meningkat pada hasil belajar saja, namun juga pada pengamalan nilai-nilai yang terkandung dalam materi yang diajarkan. Dengan begitu antara domain kognitif, afektif dan psikomotorik dapat saling bersinergi.

\section{Referensi}

Fandy's. Metode Pembelajaran Dengan Lagu. Diakses 10 Oktober 2012 dari //http.Fandi's.blogspot. 
Nuraini, Ririn. "Pengembangan Self-Esteem Sebagai Upaya Peningkatan Kinerja Pendidik di TKIT 2 Qurrota A'yun Ponorogo, "dalam Jurnal Muslim Heritage Volume 3, No. 2, November, 2018.

P. Schiller. 20 Tips Start Smart! Memompa Kecerdasann Sejak Dini. Jakarta: Erlangga, 2005.

Rohani, Imam. "Conflict Management between Students at the Integrated Islamic Elementary School Qurrota A'yun Ponorogo." In 6th International Conference on Community Development (ICCD 2019), 349:250-253. Atlantis Press, 2019.

Rokhmah, Khaniffatur. "Penggunaan Metode Sing a Song Dalam Upaya Peningkatan Motivasi dan Hasil Belajar Bahasa Inggris Siswa Kelas IV SDN Tegalsari Adimulyo Tahun Pelajaran 2013/2014, "dalam UNS-F. KIP Jur. Pendidikan Guru Sekolah Dasar-X.7211049-2016. 2016.

Salahudin, Anas. Penelitian Tindakan Kelas. Bandung: Pustaka Setia, 2015.

Sudjana, Nana. Penilaian Hasil Proses Belajar Mengajar.

Bandung: Remaja Rosdakarya, 2009

Zarkasyi, Imam. Usuluddin (Aqa'id). Bandung: Trimurti, 2014. 